\title{
Ultrasound Guided Confirmation of Endo Tracheal Intubation in Various Oral \& Faciomaxillary Surgeries
}

\author{
Dr. Vatsal Patel, Dr. Manisha Kapdi* \\ Associate professor of anaesthesia, Smt. N.H.L. Muni. Medical college, Ahmedabad, Gujarat, India \\ *Corresponding Author: Dr. Manisha Kapdi, Associate professor of anaesthesia, Smt. N.H.L. Muni. \\ Medical college, Ahmedabad, Gujarat, India. Email: manisha_kapdi @ Yahoo.com
}

\begin{abstract}
Background: Oral \& faciomaxillary surgeries are challenging as anesthesiologist share airway with surgeon. For these surgeries general Anaesthesia is required. Endotracheal intubation is gold standard for general Anaesthesia in various oral\& faciomaxillary surgeries. Detection of endotracheal intubation is crucial as missed esophageal intubation is disaster. Normally wave capnography is used for detecting endotracheal intubation. Use of Ultrasound in field of anaesthesia is getting popular since few years. We use ultrasound for detecting endotracheal intubation.
\end{abstract}

Study design: Randomised comparative observational study.

Aims \& objectives: To access efficacy of real time ultrasound to detect endotracheal tube in situ. Also to compare it with wave capnography for real time, efficacy, missed esophageal intubation, accuracy, specificity, sensitivity.

Methods: We have enrolled 60 patients in 2 groups, 30 in each group by odd and even numbers in sealed opaque envelopes randomly. Execution of randomization was done at time of giving general anaesthesia.

Group A: Ultrasound was used to detect endotracheal intubation.

Group B: Wave capnography is used for detecting endotracheal intubation.

Time to access, missed esophageal intubation, accuracy, specificity and sensitivity were noted.

Results: Out of 60 patients, 3 esophageal intubation were there. Out of 57 tracheal intubation USG assess one as esophageal intubation (false positive).

Conclusion: Ultrasound is good alternative to ETCO2 to confirm endotracheal tube even in remote setup.

\section{INTRODUCTION}

Airway management is the most important part in clinical illness [1]. The correct placement of the ET provides the absolute continuity of the airway. Location of ET must confirmed immediately after intubation clinically and assistive devices. Ignorance of the oesophageal intubation can be disastrous. Other than clinical evaluation, the most reliable method for confirming and monitoring the location of the ET tube is the continues wave capnography [2] but it is not always available and is expensive.

Ultrasound (US) has increasingly growing tool in anaesthesia and this technique has emerged as a simple, portable, fast, non-invasive tool for airway assessment and management. In addition to its common use in peripheral nerve block, central blocks, chronic pain, the role of Ultrasonography in airway management has gained significance, although still ill-defined [3].
Clinical applications of US imaging of upper airway include; identification of Et tube placement, guidance of percutaneous tracheostomy, and cricothyroidotomy, detection of subglottic stenosis, prediction of difficult intubation, and post extubation stridor, prediction of paediatric ETT ${ }^{\prime}$ and Double-lumen tube size [4]. In USG, bilateral diaphragm movements, pleural movement of the lung, imaging of tracheal tube and ET were used to confirm the location [4]. In our study, we compared USG waveform capnography to confirm ET tube placement in patients operated under general anaesthesia.

\section{MATERIAL AND MethodS}

After approval of Institutional Review board study was conducted over 60 patients of ASA grade I/II, of various oral and maxilla facial surgeries. 30 patients taken in each group who were going to operate under general anaesthesia. 
In Group A ETT confirmation done by capnography and in Group B ETT confirmed by USG. Patients below 18years of age, Mallampatti Grade 3 or 4, obese, patients with restricted neck movement were excluded.

After routine pre anaesthetic check up and written informed consent, patients were taken inside ot. A large bore i.v cannula was inserted and all routine monitors were attached. Premedication in form of Inj. Ondansetron $4 \mathrm{mg}$ iv slowly, Inj. Glycopyrrolate $0.1 \mathrm{~g}$ iv, Inj. Fentanyl $1.5 \mu \mathrm{g} / \mathrm{kg}$ iv given. General anaesthesia was given Inj. Thiopentone $6 \mathrm{mg} / \mathrm{kg}$ and Succinylcholine $2 \mathrm{mg} / \mathrm{kg}$ and Endto tracheal tube inserted according to patients age. Confirmation of Endotracheal tube was done clinically Auscultation, $\mathrm{Etco}_{2}$ Capnography and Ultrasound.

Under US, after intubation linear probe was placed horizontally over suprasternal region. Trachea, Tracheal ring and esophagus were identified. If tube is inside the trachea, two hyperechoic parallel lines are seen, Single lumen imaging can be seen; in presence of esophageal intubation, the trachea is empty with a distended esophagus and Double lumen imaging can be seen. Successful tracheal intubation was verified using the following criteria: identification of the trachea and tracheal rings, visualization of vocal cord, widening of glottis as the tracheal tube passes through, tracheal tube positioning above carina and demonstration of movement of visceroparietal pleural interface after manual ventilation of the lungs [5]. Esophageal intubation was recognized by visualization of the tube in the left paratracheal space. Endtidal $\mathrm{CO}_{2}$ was measured by a wave form capnography. It was accepted that Endotracheal intubation was present if the value after at least five ventilations was greater than $4 \mathrm{mmhg}$ in wave form capnography and if characteristic waveform was present. Time taken Wave form Capnography and US were recorded. All patients were auscultate over right and left hemithorax and Epigastric region. In auscultation, right and/or left breathing sound was accepted as Endotracheal intubation and breathing sound over Epigastric region considered as Esophageal intubation.

\section{RESUlts}

We conducted this study in our institute over 60 patients, 30 patients in each group who are going to operate under general anaesthesia. In Group A ETT confirmation done by capnography and in Group B ETT confirmed by USG. All the patients were between the 20-40year of age group. Demographic data of patients shown in Table no.1.

Table1. Demographic characteristic of patients.

\begin{tabular}{|l|l|l|l|l|}
\hline Parameters & Group A(30) & Group B(30) & Pvalue & Inference \\
\hline Age( yrs) & $28 \pm 5$ & $30 \pm 4$ & $>0.05$ & NS \\
\hline Male: female & $16: 14$ & $15: 15$ & $>0.05$ & NS \\
\hline ASA grade(1/ II) & $17: 13$ & $16: 14$ & $>0.05$ & NS \\
\hline
\end{tabular}

Out of 60 intubation, 57 were tracheal intubation and 3 were esophageal intubation. Mean Time taken for confirmation of Endo tracheal tube via

Table2. Shows Mean duration for confirmation of tube via Ultrasonography and Capnography.

\begin{tabular}{|c|c|c|c|c|}
\hline Parameters & Group A & Group B & $P$ value & Inference \\
\hline Real time of detection( $\mathrm{sec}$ ) & $9+2$ & $12+3$ & $<0.05$ & Significant \\
\hline
\end{tabular}

Tracheal USG identified 57 of these intubations as tracheal intubation. The tracheal USG identified 1 of these 57 tracheal intubations as esophageal intubation (False positive). So, specificity of Tracheal USG was $98.24 \%$ and sensitivity was $96 \%$. 3 esophageal intubation were missed by $\mathrm{ETCO}_{2}$, So specificity in $\mathrm{ETCO}_{2}$ method was $95 \%$, sensitivity is $97 \%$. 1 false positive esophageal intubation detection by US method was due to transcutaneous fat, obesity, thyroid calcification. So accuracy in US method capnography was $12+3$ sec. And via Ultra sonography it was $9 \pm 2 \mathrm{sec}$. Time taken for auscultation was $15 \pm 2 \mathrm{sec}$ in each group.

\section{DISCUSSION}

The classical methods for detecting endotracheal intubation are based on ventilation. Direct observation of the ETT passing through the glottis may not be possible when laryngoscopy is difficult ${ }^{6}$. Observation of auscultation and chest wall movements in confirming tracheal intubation is the most commonly used method, and wave form capnography is accepted as a gold standard method [6]. But waveform capnography is not always available, expensive and requires 
ventilation. Patients with full stomach may give false positive results due to gastric $\mathrm{CO}_{2}$ production, pulmonary edema, airway obstruction [7-9].

USG is a simple, portable, fast, non-invasive tool. USG can determine that the tube is in esophagus, without ventilating the patient and avoid unwanted effects [10]. If USG proven in sensitivity and specificity as capnography inn ETT confirmation, it can be used where capnography is not available. It helps in rapid assessment of the airway anatomy not only in operation theatre but also in the intensive care unit and emergency department [3].

In our study, tracheal USG correctly define tracheal intubation and esophageal intubation. USG took almost similar time in confirming the endotracheal intubation than capnography.

In Abbasi et al' s study, tracheal USG incorrectly defined tracheal intubation in a patient as esophageal intubation (false positive). They reported that this condition may be due to anatomic factors such as thyroid calcification and that some of erroneous findings may be corrected by experience, even if not under control of the user [11].

Chou et al. compared the rapid tracheal ultrasound exam (T.R.U.E.) and quantitative waveform capnography in a prospective observational study, which shows USG have high sensitivity and specificity in tube site fixation. In same study they found that real time USG performed during CPR was an adequate method of confirming the tube location [10].

USG can be used to confirm airway device placement indirectly by visualization of diaphragmatic and pleural movements which are qualitative and quantitative indicators of lung expansion. If the ET tube in correct position, bilateral equal motion of the diaphragm toward the abdomen synchronized with ventilation can be observed [12]. By positioning prob in the intercostal space lung chest wall interface is seen called lung sliding sign. If the tube is endobronchial, movement of diaphragm and lung sliding sign is present on ventilated lung and absent in contralateral side. If the tube is in the esophagus, there is no expansion of the lung or movement of diaphragm [13].

\section{CONCLUSION}

Ultrasonography is a safe, quick, non invasive, portable and repeatable technique, which shows real time dynamic images. It took almost similar time in confirmation of endotracheal tube than capnography though capnography is a gold standard method for confirmation. USG can replace capnography in confirming ETT placements in centres without capnography. This can prevent unrecognised esophageal intubation.

\section{LIMITATION}

Our study has some limitation. Our study was done in Oral surgery cases and therefore number of patients and number of esophageal intubation is low.

\section{REFERENCES}

[1] Blanda M, Gallo UE (2003) Emergency airway management. Emerg Med Clin N Am 21: 1-26.

[2] American Heart Association. (2006) 2005 American Heart Association (AHA) Guidelines for Cardiopulmonary Resuscitation (CPR) and Emergency Cardiovascular Care (ECC) of Pediatric and Neonatal Patients: Pediatric Advanced Life Support. Journal Article in Pediatrics 117: e1005 to e1028.

[3] Terkawi AS, Karakitsos D, Elbarbary M, et al., Ultrasound for the anaesthesiologists: present and future. Sci World J. 2013;2013:683-5.

[4] Kundra P, Mishra SK, Ramesh A. Ultrasound of the airway. Indian J Anaesth 2011;55:456-62.

[5] Marciniak B, Fayuoux P, Hebrard A, et al. Airway management in children: Ultrasonography assessment of tracheal intubation in real time? Anesth Analg. 2009;108:461-5.

[6] Abhishek C, Munta K, Rao SM, et al. End-tidal capnography and upper airway Ultrasonography in the rapid confirmation of endotracheal tube placement in patients requiring intubation for general anaesthesia. Indian $\mathrm{J}$ Anaesth. 2017;61:486-9.

[7] Sayah AJ, Peacock WF, Overton DT (1990) End-tidal $\mathrm{CO} 2$ measurement in the detection of esophageal intubation during cardiac arrest. Ann Emerg Med 19: 857-860.

[8] Takeda T, Tanigawa K, Tanaka H, Hayashi Y, Goto E, et al. (2003) The assessment of three methods to verify tracheal tube placement in the emergency setting. Resuscitation 56: 153-157.

[9] Levine RL, Wayne MA, Miller CC (1997) Endtidal carbon dioxide and outcome of out-ofhospital cardiac arrest. N Engl J Med. 337:301306. 
[10] Chou HC, Tseng WP, Wang CH, Ma MHM, Wang HP, et al. (2011) Tracheal rapid ultrasound exam (T.R.U.E.) for confirming ETT placement during emergency intubation. Resuscitation 82: 1279-1284.

[11] Abbasi S, Farsi D, Zare MA, Hajimohammadi M, Rezai M, et al. (2015) Direct ultrasound methods: a confirmatory technique for proper endotracheal intubation in the emergency department. Eur J Emerg Med 22:10-16.
[12] Hsieh KS, Lee CL, Lin CC, et al. Secondary confirmation of endotracheal tube position by ultrasound image. Crit Care Med. 2004;32:S374-7.

[13] Sim SS, Lien WC, Chou HC, et al. Ultrasonographic lung sliding sign confirming proper endotracheal intubation during emrgnecy intubation. Resuscitation. 2012;83:307-12.

Citation: Dr. Vatsal Patel, Dr. Manisha Kapdi. Ultrasound Guided Confirmation of Endo Tracheal Intubation in Various Oral \& Faciomaxillary Surgeries. ARC Journal of Dental science. 2019; 4(3):16-19. doi:dx.doi.org/10.20431/2456-0030.0403004.

Copyright: (C) 2019 Authors. This is an open-access article distributed under the terms of the Creative Commons Attribution License, which permits unrestricted use, distribution, and reproduction in any medium, provided the original author and source are credited. 